Article

\title{
Functionalized Poly(arylene ether nitrile) Porous Membrane with High Pb(II) Adsorption Performance
}

\author{
Xiaocan Liu, Meirong Zhou, Xuefei Zhou, Lingling Wang and Xiaobo Liu * \\ Research Branch of Advanced Functional Materials, School of Materials and Energy, \\ University of Electronic Science and Technology of China, Chengdu 61173, China \\ * Correspondence: liuxb@uestc.edu.cn; Tel.: +86-28-8320-7326
}

Received: 30 July 2019; Accepted: 26 August 2019; Published: 28 August 2019 updates

\begin{abstract}
Porous materials with high specific surface area possess a broad application prospect in the treatment of wastewater. In this work, sulfonated poly(arylene ether nitrile) (SPEN) functionalized with a carboxylic acid group was successfully synthesized, which was subsequently transformed into SPEN porous membranes with cetyltrimethyl ammonium bromide (CTAB) as pore-forming agents to study the adsorption performance for lead ions in aqueous solution. Then, experiments were conducted to investigate the effect of $\mathrm{pH}$, contact time and initial solution concentration on the adsorption performance of porous membranes, and the adsorption capacities of porous membranes with different content $(0,5$ and $15 \mathrm{wt} \%)$ of CTAB were $183.60,161.73$ and $127.43 \mathrm{mg} / \mathrm{g}$, respectively, which manifested that the adsorption capacity decreased with the increase of CTAB. The adsorption capacities of porous membranes increased with the increase of the initial concentration of lead ions, and the maximum reached was $246.96 \mathrm{mg} / \mathrm{g}$. The simulation of adsorption kinetics revealed that the adsorption was accorded with the pseudo-second-order kinetic model and Langmuir equation, indicating that the adsorption process followed Langmuir monolayer adsorption. Thermogravimetric analysis demonstrated that the porous membranes had excellent thermodynamic properties both before and after adsorption. In addition, the change of adsorption peak in the Attenuated Total Reflectance Fourier Transform Infrared Spectroscopy (ATR-FTIR) spectrum indicated that the absorption performance of porous membranes for lead ions benefited from the chelation between lead ions and the carboxylic acid group on SPEN. Moreover, the porous membranes maintained excellent adsorption properties after circulating five times under the conditions of acidic or alkaline, and the cycle regeneration effect was outstanding.
\end{abstract}

Keywords: sulfonated poly(arylene ether nitrile); adsorption; lead ions; cetyltrimethyl ammonium bromide

\section{Introduction}

The rapid development of modern industry brings wealth to society, but it also causes damage to the environment at the same time. Heavy metal ion pollution is particularly serious, which is mainly induced by unscrupulous discharge sewage of industrial effluent without treatment [1]. Industrial waste water contains a variety of harmful heavy metal ions, such as lead ions, cadmium ions and chromium ions, which will exist in the biosphere for a long time and endanger the environment [2]. Particularly, the aforementioned heavy metal ions are harmful to human health. Lead is considered as one of the most toxic heavy metal ions, on account of its wide distribution in the environment and chemical toxicity to various organisms. Low concentrations of lead ions are harmful to the liver, nervous system and kidneys, which can cause abdominal pain, kidney problems, headaches, neurological disorders and even cancer. However, with the application of lead in battery, electroplating, mining, metal processing and other industries, lead ions are constantly produced. Therefore, the problem of wastewater contaminated with lead ions needs to be solved urgently [3,4]. 
At present, commonly used methods to remove heavy metals include chemical precipitation $[5,6]$, coagulation [7], electrolytic process [8,9], biological method [10,11], ion exchange method [12], adsorption $[13,14]$ and so on. Nevertheless, the methods mentioned above have some drawbacks, such as high cost, high toxicity, large installation space requirements and even bring in secondary pollution [15]. Recently, membrane separation technology has been generally applied in many water treatment fields $[16,17]$. Membrane technology has received considerable attention because of the advantages of its technical simplicity and environmental compatibility. It is known that a large surface area and adequate adsorption site for membranes are critical for membrane technology in water treatment processes. Therefore, separation membranes with a porous structure and specific functional groups (such as sulfonic acid group, carboxyl group, hydroxyl group, etc.) have attracted the attention of many researchers $[18,19]$. The separation process is simple and efficient and can be synchronized with other separation and purification processes. Particularly, no additives are required during membrane separation [20]. Moreover, the introduction of a surfactant in the preparation process has been acknowledged to be an efficient method for increasing the porosity of a porous membrane [21,22].

Poly(arylene ether nitrile) (PEN), as a special engineering material, possesses excellent thermal stability, corrosion resistance and maneuverability on account of its rigid benzene ring structure and adjustable side chain $[23,24]$. Meanwhile, it can be prepared into microspheres, fibers, membranes, etc., owing to the diversity of its preparation processes. On the basis of sulfonated poly(arylene ether nitrile) (SPEN) containing sulfonic acid and carboxylic acid groups, the synthesized SPEN membrane exhibits high sensitivity to copper ions $\left(\mathrm{Cu}^{2+}\right)$ and the newly fabricated SPEN absorbent is found to be efficient in the selective adsorption of cationic dyes [25,26].

In this work, SPEN containing carboxylic acid groups in the side chains was synthesized, leading to further fabrication of the porous membrane with different amounts of cationic surfactant cetyltrimethyl ammonium bromide (CTAB). In the preparation of the porous membrane, different proportions of CTAB were added to study the effect of cationic surfactant on the adsorption of lead ions in an aqueous solution. Then the porous membrane with the largest adsorption capacity for lead ions was systematically studied in combination with isothermal adsorption. Furthermore, we also studied the influence of $\mathrm{pH}$, contact time and initial concentration on the adsorption capacity for $\mathrm{Pb}$ (II) and adsorption mechanism of the porous membrane for $\mathrm{Pb}(\mathrm{II})$. Compared with other works, we used a new polymer to fabricate the porous membrane, and then the ability of porous membranes to remove lead ions under various conditions was studied experimentally. Moreover, the adsorption capacity for lead ions by porous membranes was higher than that of other literature [27-33].

\section{Materials and Methods}

\subsection{Materials}

Hydroquinone sulfonic acid potassium salt (SHQ) and 2,6-difluorobenzonitrile (DFBN) were purchased from Shanghai Sigma Aldrich (Shanghai, China). Phenolphthalein (PP), sodium hydroxide $(\mathrm{NaOH}, \mathrm{AR})$, zinc $(\mathrm{Zn}), \mathrm{N}$-methyl pyrrolidone $(\mathrm{NMP}, \mathrm{AR})$, potassium carbonate $\left(\mathrm{K}_{2} \mathrm{CO}_{3}, \mathrm{AR}\right)$, ethanol, toluene, cetyltrimethyl ammonium bromide $(\mathrm{CTAB})$ and lead nitrate $\left(\mathrm{PbNO}_{3}\right)$ were supplied by Chengdu Kelong Chemical Reagent Company (Chengdu, China).

\subsection{SPEN and Porous Membrane Preparation}

Firstly, phenolphthalein (PPL) was synthesized from PP, NaOH and Zn [34]. Then, PPL (22.4 g, $0.07 \mathrm{~mol})$, SHQ (6.84 g, $0.03 \mathrm{~mol})$, DFBN (13.9 g, $0.1 \mathrm{~mol}), \mathrm{K}_{2} \mathrm{CO}_{3}(28 \mathrm{~g}), \mathrm{NMP}(65 \mathrm{~mL})$ and toluene $(25 \mathrm{~mL})$ were added to a three-necked flask. Among them, PPL, SHQ and DFBN were the raw materials for the synthesis of SPEN, NMP was the solvent, $\mathrm{K}_{2} \mathrm{CO}_{3}$ acted as a catalyst to facilitate polymerization and toluene was the dehydrating agent. They were evenly mixed and then heated up to $145^{\circ} \mathrm{C}$ and maintained for $3 \mathrm{~h}$ in the stage of dehydration. Then, the temperature was slowly raised to $180^{\circ} \mathrm{C}$ and kept for $1 \mathrm{~h}$. At the end of the polymerization, the product was precipitated in ethanol. Then, the 
product was sequentially washed with ethanol, hydrochloric acid and deionized water to remove the unreacted raw materials, such as PPL, SHQ, DFBN and $\mathrm{K}_{2} \mathrm{CO}_{3}$. Finally, the product was dried in a vacuum oven at $80^{\circ} \mathrm{C}$ [35].

First, the synthesized SPEN accompanied by 0,5 and $15 \mathrm{wt} \%$ CTAB were dissolved in NMP and coated on a glass plate by a $200 \mu \mathrm{m}$ applicator, respectively. NMP was the solvent, and CTAB was a kind of hydrophilic surfactant, which can reduce the interfacial tension between the membrane and water, so as to promote the growth of pores. This was the dissolution process, in which there was no phase change. Second, the liquid film was immersed into a coagulation bath ( $\mathrm{HCl}$ solution). Then, due to the diffusion exchange of the solvent (NMP) and nonsolvent ( $\mathrm{HCl}$ solution), the solubility of polymer in the system decreased and thermodynamics changed, and phase separation occurred. Finally, the porous membrane was soaked in a coagulation bath for $24 \mathrm{~h}$. After the obtained porous membranes were immersed in $1 \mathrm{~mol} / \mathrm{L} \mathrm{NaOH}$ solution for $2 \mathrm{~h}$, they were washed with deionized water to remove the residual $\mathrm{NaOH}$ and then dried in an oven for the next applications. The resulting porous membranes with different CTAB content were named as SPEN-CTAB- $0 \%$, SPEN-CTAB- $5 \%$ and SPEN-CTAB- $15 \%$.

\subsection{Adsorption Behaviour for $\mathrm{Pb}(\mathrm{II})$}

The effect of $\mathrm{pH}(3,4,5,6,7)$, CTAB content $(0,5,15 \mathrm{wt} \%)$, contact time $(0,5,15,30,60,90$, $120 \mathrm{~min}$ ) and initial concentration $(50,70,100,150,200 \mathrm{mg} / \mathrm{L})$ to the adsorption behavior of the porous membrane for $\mathrm{Pb}(\mathrm{II})$ were investigated. In a typical experiment, $25 \mathrm{mg}$ SPEN-CTAB- $0 \%$ was immersed in $200 \mathrm{mg} / \mathrm{L} \mathrm{PbNO}_{3}$ solution, the $\mathrm{pH}$ values were regulated by a solution of $0.1 \mathrm{~mol} / \mathrm{L} \mathrm{HCl}$ and $0.1 \mathrm{~mol} / \mathrm{L}$ $\mathrm{NaOH}$. Then, adsorption experiments were carried out using three different CTAB content porous membranes $(25 \mathrm{mg})$ in $150 \mathrm{~mL}$ of a $70 \mathrm{mg} / \mathrm{L} \mathrm{PbNO}_{3}$ solution. Functionalized adsorption for $\mathrm{Pb}$ (II) from aqueous solution was measured by kinetics similar to adsorption isotherms. The concentration of $\mathrm{Pb}$ (II) was measured by inductively coupled plasma optical emission spectrometer (ICP-OES). Moreover, $0.1 \mathrm{~mol} / \mathrm{L} \mathrm{HCl}$ solution, $0.2 \mathrm{~mol} / \mathrm{L} \mathrm{NaOH}$ solution and deionized water were used as regeneration agents for the adsorption-desorption cycle experiment, respectively. All adsorption experiments were carried out at $298.15 \mathrm{~K}$ with the $\mathrm{pH}$ at 5 . The instantaneous adsorption amount $\left(q_{\mathrm{t}}\right)$ and equilibrium adsorption amount $\left(q_{\mathrm{e}}\right)$ of $\mathrm{Pb}(\mathrm{II})$ were calculated by Equations (1) and (2) [26]:

$$
\begin{aligned}
& q_{\mathrm{t}}=\left(\frac{C_{0}-C_{\mathrm{t}}}{m}\right) \times V \\
& q_{\mathrm{e}}=\left(\frac{C_{0}-C_{\mathrm{e}}}{m}\right) \times V
\end{aligned}
$$

where $C_{0}(\mathrm{mg} / \mathrm{L}), C_{\mathrm{t}}(\mathrm{mg} / \mathrm{L})$ and $C_{\mathrm{e}}(\mathrm{mg} / \mathrm{L})$ are the initial concentration of $\mathrm{Pb}(\mathrm{II})$, the residual concentration at time $t(\mathrm{~min})$ and the residual concentration at the time of adsorption equilibrium, respectively. $V(\mathrm{~mL})$ is the volume of the $\mathrm{Pb}(\mathrm{II})$ solution, and $m(\mathrm{mg})$ is the mass of the porous membrane.

\subsection{Characterization}

The structure and composition of SPEN were determined by Bruker AV II-400 spectrometer and Fourier transform infrared spectroscopy (FTIR and ATR-FTIR) instrument (Shimadzu 8400S, Kyoto, Japan). Among them, the Bruker AV II-400 spectrometer measured the ${ }^{1} \mathrm{H}$ NMR (400 MHz) spectra relative to DMSO-d6 $(\mathrm{H}: \mathrm{d}=2.50 \mathrm{ppm})$ as a reference to measure the SPEN nuclear magnetic spectrum. Thermal stability of SPEN was determined by Thermogravimetric Analysis TGA-Q50 (TA Instruments, Newcastle, DE, USA). The weight-average molecular weight $\left(M_{\mathrm{W}}\right)$, number average molecular weight $\left(M_{n}\right)$ and polydispersity index (PDI; $M_{\mathrm{w}} / M_{\mathrm{n}}$ ) of SPEN were measured by gel permeation chromatography (GPC) with polystyrene as the standard sample by PL-GPC220 system. The cross-section and surface microstructure of the three porous membranes were characterized by scanning electron microscopy (SEM) (JSM-6490LV, JEOL, Akishima, Japan). The hydrophilicity of the porous membrane was characterized by measuring the contact angle of the porous membrane surface at room temperature. The equilibrium water content $(\mathrm{EWC})$ and porosity of the porous membrane 
were calculated from Equations (3) and (4) by measuring the water absorption (298.15 K, $24 \mathrm{~h}$ ) of the porous membrane in deionized water [36]:

$$
\begin{gathered}
\operatorname{EWC}(\%)=\frac{W_{\mathrm{w}}-W_{\mathrm{d}}}{W_{\mathrm{w}}} \times 100 \\
\text { Porosity }=\frac{W_{\mathrm{w}}-W_{\mathrm{d}}}{\rho_{\mathrm{w}} \times V}
\end{gathered}
$$

where $W_{\mathrm{w}}(\mathrm{g})$ and $W_{\mathrm{d}}(\mathrm{g})$ are the masses of dry membrane and wet membrane, respectively. $\rho_{\mathrm{W}}\left(\mathrm{g} / \mathrm{cm}^{3}\right)$ is the density of water, and $V\left(\mathrm{~cm}^{3}\right)$ is the volume of the wet membrane. Moreover, the porosities of different membranes were tested by an automatic mercury injection apparatus (Micromeritics Instrument Corporation, IV9500, Norcross, GA, USA). The Pb(II) concentration was tested by ICP-OES (Peakinelmer Optima 7300, Waltham, MA, USA).

\section{Results and Discussion}

\subsection{Characterization of SPEN}

The synthesis process of SPEN via nucleophilic substitution reaction is displayed in Figure 1a and the infrared spectrum of raw SPEN is shown in Figure 1b. It was clear that the absorption peak at $2230 \mathrm{~cm}^{-1}$ was ascribed to the stretching bond of $-\mathrm{CN}$, the peak at $1701 \mathrm{~cm}^{-1}$ was the stretching of $-\mathrm{COOH}$, and the peaks at 1576 and $1450 \mathrm{~cm}^{-1}$ were attributed to the stretching vibration of the benzene ring. The ether bond absorption peak was observed at $1245 \mathrm{~cm}^{-1}$ and sulfonic acid absorption peak was located at 1075-1024 $\mathrm{cm}^{-1}$ [26,34]. From the nuclear magnetic resonance spectrum in Figure 1d, the peak at $12.98 \mathrm{ppm}$ was the characteristic peak of $\mathrm{H}$ on $-\mathrm{COOH}$, the characteristic peaks of $\mathrm{H}$ on the benzene ring were located around $6.39-7.80 \mathrm{ppm}$, characteristic peaks of $\mathrm{C}-\mathrm{H}$ varied from 1.04 to $2.68 \mathrm{ppm}$. Figure $1 \mathrm{c}$ is the TGA curves of raw SPEN and $5 \%$ weight loss temperature was $430{ }^{\circ} \mathrm{C}$, which revealed that the prepared SPEN possessed excellent thermal stability. $M_{\mathrm{W}}, M_{\mathrm{n}}$ and PDI of SPEN measured by GPC were 59,342, 69,221 g/mol and 1.166, respectively.
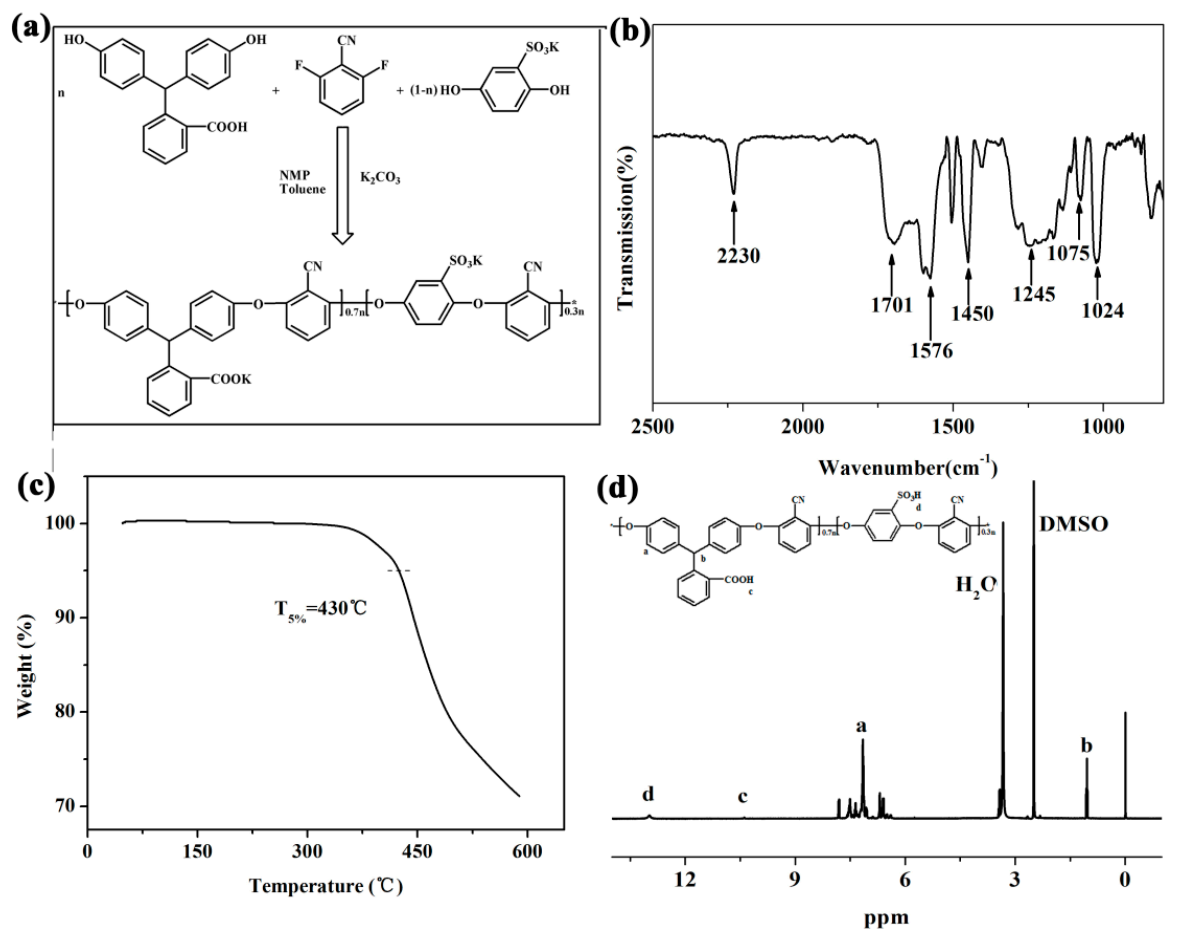

Figure 1. Synthesis route (a) FTIR (b), TGA curves and (c) ${ }^{1} \mathrm{H}$ NMR spectra (d) of raw sulfonated poly(arylene ether nitrile) (SPEN). 


\subsection{Structure Characterization of Porous Membrane}

The cross-section and surface morphology of the porous membranes are demonstrated in Figure 2. Figure $2 \mathrm{a}-\mathrm{c}$ show the cross-sectional morphology of three different porous membranes with a scale of $40 \mu \mathrm{m}$, respectively. Figure 2a1-c1 show the cross-sectional morphology of different porous membranes at $10 \mu \mathrm{m}$. It can be seen that the porous membranes consist of a dense top layer and porous supporting layer, and the porous supporting layer is the subject part of the porous membrane. From Figure 2a-c, the pore size in the porous supporting layer of SPEN-CTAB-15\% was significantly increased compared to SPEN-CTAB- $0 \%$ and SPEN-CTAB- $5 \%$. Therefore, it can be obtained that the pore diameter in the porous supporting layer of the porous membrane accordingly increased as the increase of the proportion of surfactant CTAB. However, with the increases of $C T A B$, the pores of the dense top layer decreased and became denser by comparing the surface morphologies of different porous membranes (Figure 2a-c2).


Figure 2. Cross-section SEM images of SPEN-CTAB-0\% (a), (a1); SPEN-CTAB-5\% (b), (b1); SPEN-CTAB-15\% (c), (c1). Surface SEM images of SPEN-CTAB-0\% (a2), SPEN-CTAB-5\% (b2) and SPEN-CTAB-15\% (c2). CTAB: cetyltrimethyl ammonium bromide.

The water absorption of porous membranes containing different proportions of CTAB is shown in Figure 3. The equilibrium water content and porosity is displayed in Table 1. It can be seen from Figure 3 that both the water absorption rate and surface contact angle of the porous membrane increased with the increase in additional CTAB content. The water absorption rates of SPEN-CTAB-0\%, SPEN-CTAB-5\% and SPEN-CTAB-15\% were 283, 285 and $385 \mathrm{wt} \%$, respectively. Furthermore, the contact angles were $54.7^{\circ}, 61.9^{\circ}$ and $70.6^{\circ}$, respectively. The EWC and porosity in Table 1 also increased as CTAB increased, and the highest porosity reached $83.60 \%$. Moreover, the porosities of SPEN-CTAB- $0 \%$, SPEN-CTAB- $5 \%$ and SPEN-CTAB- $15 \%$ which were tested by an automatic mercury injection apparatus were $71.98 \%$, $75.53 \%$ and $83.14 \%$, respectively. The result was consistent with the porosity calculated by Equation (4).

With the augment of $\mathrm{CTAB}$, the equilibrium water content and porosity accordingly increased, which conformed to the increase of pore size in the porous supporting layer (Figures 2 and 3). Furthermore, the increase in $\mathrm{CTAB}$ concentration assisted the porous membrane with a denser surface morphology, which also contributed to the increase of the contact angle. 

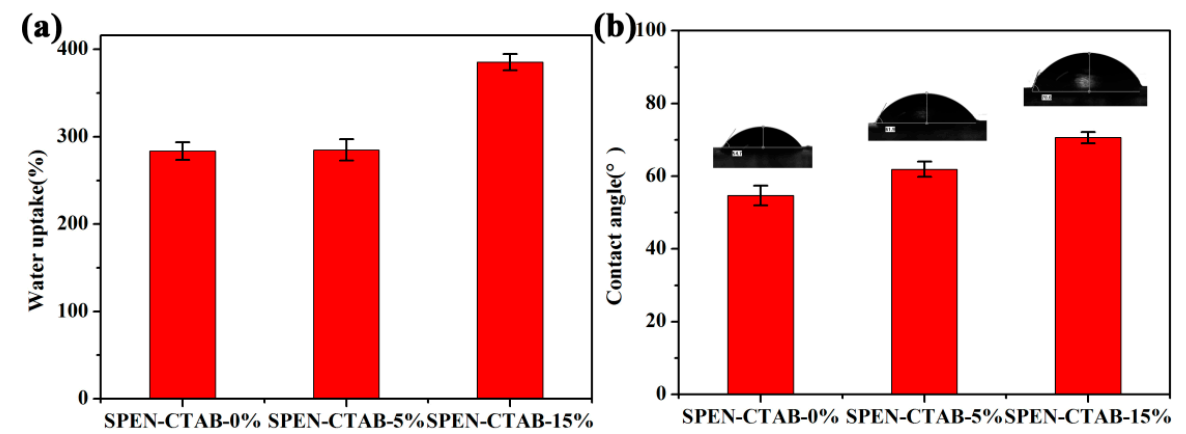

Figure 3. The water uptake (a) and contact angle (b) of SPEN-CTAB- $\%$, SPEN-CTAB-5\% and SPEN-CTAB-15\%.

Table 1. The equilibrium water content (EWC), porosity obtained from Equation (4) and contact angle of SPEN-CTAB-0\%, SPEN-CTAB-5\% and SPEN-CTAB-15\%.

\begin{tabular}{cccc}
\hline Membrane & EWC (\%) & Porosity (\%) & Contact Angle $\mathbf{(}^{\circ}$ ) \\
\hline SPEN-CTAB-0\% & 73.93 & 78.95 & 54.7 \\
SPEN-CTAB-5\% & 74.02 & 79.03 & 61.9 \\
SPEN-CTAB-15\% & 79.40 & 83.60 & 70.6 \\
\hline
\end{tabular}

\subsection{Effect of Solution $\mathrm{pH}$}

The effect of solution $\mathrm{pH}$ on the adsorption capacity for $\mathrm{Pb}(\mathrm{II})$ using SPEN-CTAB- $0 \%$ under $200 \mathrm{mg} / \mathrm{L} \mathrm{Pb}$ (II) aqueous solution and a contact time of $2 \mathrm{~h}(298.15 \mathrm{~K})$ is shown in Figure 4 . It can be concluded from Figure 4 that the adsorption capacity was distinctly affected by $\mathrm{pH}$ values. The adsorption capacity increased with the $\mathrm{pH}$ increasing from 3 to 6 , while the adsorption capacity decreased with the continuous increase of $\mathrm{pH}$ values from 6 to 7 . The results may be induced by the competition between $\mathrm{H}_{3} \mathrm{O}^{+}$and $\mathrm{Pb}(\mathrm{II})$ at $\mathrm{pH} 3$ and 4 , the protonation of $-\mathrm{COOH}$ and $-\mathrm{SO}_{3} \mathrm{H}$ groups under strong acidic conditions which resulted in low adsorption capacity [27], and the formation of hydroxyl complexes hinders the chelation between $\mathrm{Pb}$ (II) and a functional group at a high $\mathrm{pH}$ value [31]. The maximum adsorption capacity was up to $313.81 \mathrm{mg} / \mathrm{g}$ at $\mathrm{pH} 6$. However, the spontaneous precipitation of $\mathrm{Pb}(\mathrm{II})$ would come up and generate $\mathrm{Pb}(\mathrm{OH})_{2}$ sediment when the $\mathrm{pH}$ value was 6 and higher. Therefore, after this experiment $\mathrm{pH}$ values were set as 5, which is also a familiar $\mathrm{pH}$ value in industrial wastewater [30]. Although the adsorption capacity would be reduced when the optimal $\mathrm{pH}$ value was not reached, the adsorption capacity was still considerable in general. Moreover, the experimental results would not be disturbed by the hydroxyl complexes of $\mathrm{Pb}(\mathrm{II})$, which was relatively reliable.

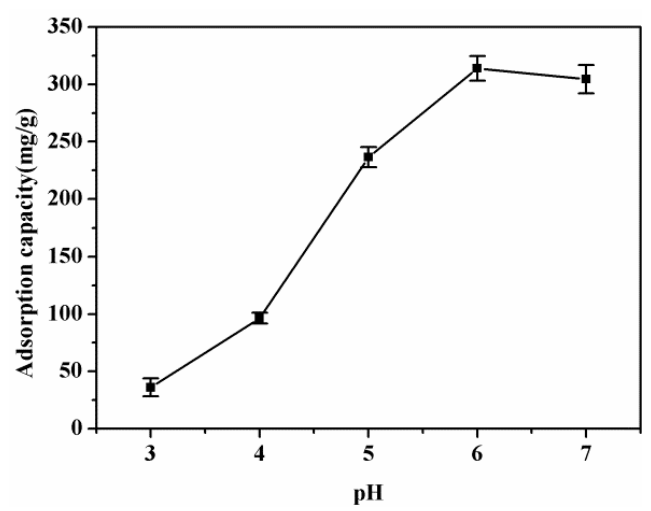

Figure 4. Effect of $\mathrm{pH}$ on the adsorption capacity using SPEN-CTAB-0\%. 


\subsection{Effect of CTAB Content in a Porous Membrane}

The effects of contact time on the adsorption of porous membranes with different CTAB ratios were studied at definite time intervals ranging from 0 to $120 \mathrm{~min}$. All adsorption experiments were carried out by placing $25 \mathrm{mg}$ of SPEN porous membranes into $150 \mathrm{~mL}$ of $70 \mathrm{mg} / \mathrm{L} \mathrm{PbNO} 3$ solution. As shown in Figure 5a, the adsorption capacity increased rapidly in the first $30 \mathrm{~min}$ and reached an adsorption equilibrium in $1 \mathrm{~h}$. The initial rapid adsorption of $\mathrm{Pb}(\mathrm{II})$ indicated a high affinity between $\mathrm{Pb}(\mathrm{II})$ and the porous membranes, which may be attributed to the large surface area of the SPEN porous membranes that enhance the exposure of functional groups. The equilibrium adsorption capacities of SPEN-CTAB-0\%, SPEN-CTAB-5\% and SPEN-CTAB-15\% were 183.6, 161.4 and $127.4 \mathrm{mg} / \mathrm{g}$, respectively. In order to better understand the adsorption behavior, the adsorption data were analyzed on the basis of two commonly used kinetic models, namely the first-order kinetic model and second-order kinetic model shown in Equations (5) and (6), respectively [23,26]:

$$
\begin{gathered}
\log \left(q_{\mathrm{e}}-\mathrm{q}_{\mathrm{t}}\right)=\log q_{\mathrm{e}}-\frac{k_{1}}{2.303} t \\
\frac{t}{q_{\mathrm{t}}}=\frac{1}{k_{2} q_{\mathrm{e}}^{2}}+\frac{t}{q_{\mathrm{e}}}
\end{gathered}
$$

where $t(\mathrm{~min})$ is the adsorption time, $k_{1}\left(\mathrm{~min}^{-1}\right)$ is the rate constant of pseudo-first-order and $k_{2}(\mathrm{~g} / \mathrm{mg} \mathrm{min})$ is the rate constant of pseudo-second-order.
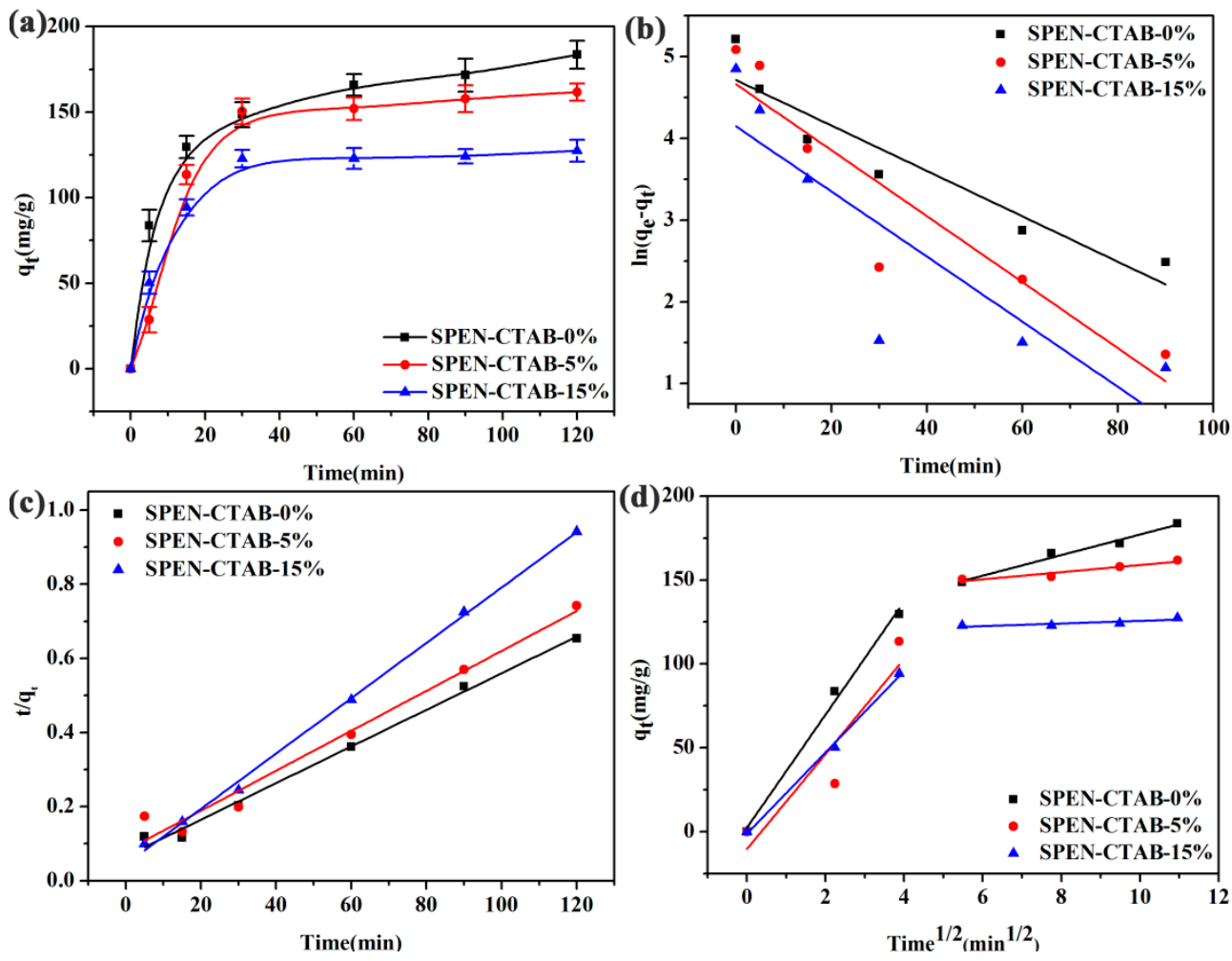

Figure 5. (a) Effect of contact time on $\mathrm{Pb}(\mathrm{II})$ adsorption capacity, (b) pseudo-first-order, (c) pseudo-second-order, and (d) intraparticle diffusion kinetic models (d) for the adsorption of $\mathrm{Pb}$ (II) onto SPEN-CTAB-0\%, SPEN-CTAB-5\% and SPEN-CTAB-15\%, respectively.

Figure $5 b, c$ show the pseudo-first-order kinetics model fitting and the pseudo-second-order kinetic model fitting of the porous membrane for $\mathrm{Pb}(\mathrm{II})$, and the relevant parameters of the kinetic fitting are listed in Table 2. From Figure 5b,c and the correlation coefficients in Table 2, it can be clearly seen that the adsorption kinetics of $\mathrm{Pb}$ (II) by the three porous membranes are all consistent with 
the second-order kinetic model. The $R^{2}$ of SPEN-CTAB- $0 \%$, SPEN-CTAB- $5 \%$ and SPEN-CTAB- $15 \%$ calculated by the pseudo-second-order kinetic model were $0.9911,0.9693$ and 0.9978 , respectively. Furthermore, the theoretical adsorption capacity obtained by pseudo-second-order kinetic model was close to the experimentally measured adsorption capacity. Therefore, the adsorption process of $\mathrm{Pb}$ (II) by the porous membrane followed the pseudo-second-order model, which indicated that the adsorption process was rapid and probably dominated by chemical adsorption [26,37].

Table 2. The kinetic parameters of adsorption of $\mathrm{Pb}(\mathrm{II})$ onto SPEN-CTAB- $0 \%$, SPEN-CTAB-5\% and SPEN-CTAB-15\%.

\begin{tabular}{ccccc}
\hline Membrane & Parameters & SPEN-CTAB-0 $\%$ & SPEN-CTAB-5\% & SPEN-CTAB-15\% \\
\hline Pseudo-first-order & $k_{1}\left(\mathrm{~min}^{-1}\right)$ & 0.0278 & 0.0404 & 0.0398 \\
& $q_{\mathrm{e}}(\mathrm{cal}).(\mathrm{mg} / \mathrm{g})$ & 12.811 & 12.678 & 11.274 \\
& $q_{\mathrm{e}}(\mathrm{exp}).(\mathrm{mg} / \mathrm{g})$ & 183.60 & 161.73 & 127.43 \\
Pseudo-second-order & $R^{2}$ & 0.8703 & 0.8320 & 0.6967 \\
& $k_{2}(\mathrm{~g} / \mathrm{mg} \cdot \mathrm{min})$ & 0.00037 & 0.00036 & 0.0012 \\
& $q_{\mathrm{e}}(\mathrm{cal}).(\mathrm{mg} / \mathrm{g})$ & 202.43 & 185.53 & 134.05 \\
& $q_{\mathrm{e}}(\mathrm{exp}).(\mathrm{mg} / \mathrm{g})$ & 183.60 & 161.73 & 127.43 \\
Intraparticle diffusion & $R^{2}$ & 0.9911 & 0.9693 & 0.9978 \\
& $k_{i 1}$ & 33.697 & 28.316 & 24.236 \\
& $C$ & 2.4810 & -10.281 & -1.170 \\
& $R_{1}^{2}$ & 0.9879 & 0.7428 & 0.9948 \\
& $k_{i 2}$ & 6.1267 & 2.1267 & 0.7810 \\
& $R_{2}^{2}$ & 115.84 & 137.61 & 117.76 \\
\hline
\end{tabular}

From the data, as the ratio of CTAB increased, the adsorption capacity of the porous membrane for $\mathrm{Pb}$ (II) decreased. This was probably because the cationic surfactant CTAB consumed certain adsorption sites of a functional group (-COO) on the SPEN membrane for further adsorption. In addition, micelles may have accumulated on the membrane surface and caused membrane contamination [38,39]. The steps of the adsorption process are generally studied by an intermolecular diffusion model, as in Equation (7) [26]:

$$
q_{\mathrm{t}}=k_{i} t^{0.5}+\mathrm{C}
$$

where $k_{i}$ is the diffusion rate constant and $C$ is the intercept that is influenced by the thickness of the boundary layer. Figure $5 \mathrm{~d}$ is an intermolecular diffusion model fitting and the parameters are listed in Table 2. It can be seen from the fitted graph that the whole adsorption process for $\mathrm{Pb}$ (II) can be divided into two stages: firstly adsorbing on the surface and then slowly diffusing into the pores of the membrane. Moreover, the two curves did not pass the origin, indicating that the internal diffusion was not the only speed control step in the entire adsorption process.

\subsection{Effect of Initial Concentrations}

Next, the $\mathrm{PbNO}_{3}$ solutions with concentrations ranging from 50 to $200 \mathrm{mg} / \mathrm{L}$ were prepared, and the adsorption capacity and adsorption kinetics of SPEN-CTAB- $0 \%$ to $\mathrm{Pb}$ (II) at different initial concentrations were simulated. From Figure $6 \mathrm{a}$, the adsorption reached equilibrium in half an hour, and the adsorption rate was fast in the whole adsorption process. In addition, the maximum adsorption capacities of the porous membrane continuously increased along with the increase in initial concentrations.

The equilibrium adsorption amounts of SPEN-CTAB- $0 \%$ in the presence of $\mathrm{Pb}$ (II) solutions with the concentrations from 50 to $200 \mathrm{mg} / \mathrm{L}$ were 195.82, $196.09202 .99,217.92$ and $246.96 \mathrm{mg} / \mathrm{g}$, respectively, which were outstanding and larger than those of reported adsorbents for $\mathrm{Pb}$ (II) removal by other researchers as demonstrated in Table 3. The corresponding results of adsorption kinetics (Figure 6b,c) and the intermolecular diffusion model (Figure $6 \mathrm{~d}$ ) for $\mathrm{Pb}$ (II) are listed in Table 4 . The $R^{2}$ of the pseudo-second-order kinetic model are $0.9896,0.9975,0.9978,0.9990$ and 0.9951 , respectively. The 
maximum adsorption capacity obtained by pseudo-second-order kinetics model was close to the experimental value. Therefore, the adsorption process mainly followed the chemisorption mechanism and involved electron sharing or electron transfer between the adsorbent and adsorbate. It can be seen from Figure $6 \mathrm{~d}$ that the whole adsorption process was also divided into two stages, and the fitting curve did not pass through the origin, so the intermolecular process was not the rate limiting step in the adsorption process.
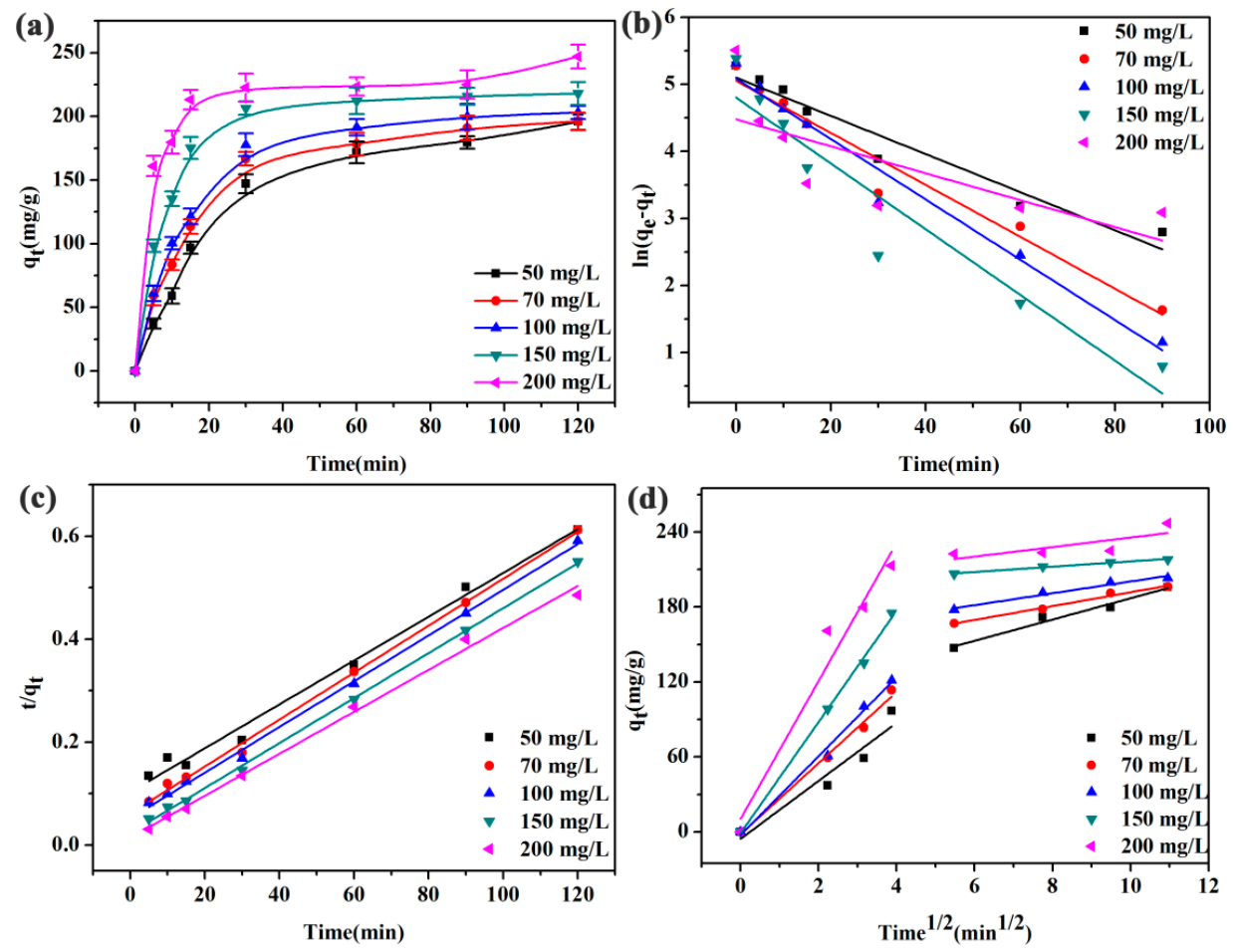

Figure 6. (a) Effect of initial concentrations on $\mathrm{Pb}(\mathrm{II})$, (b) pseudo-first-order, (c) pseudo-second-order, and $(\mathbf{d})$ and intraparticle diffusion for the adsorption of $\mathrm{Pb}(\mathrm{II})$ onto SPEN-CTAB- $0 \%$.

Table 3. Adsorption capacities of $\mathrm{Pb}(\mathrm{II})$ on various adsorbents.

\begin{tabular}{cccc}
\hline Adsorbent & $\mathbf{p H}$ & $\mathbf{P b}(\mathrm{II})$ Adsorption Capacity $\mathbf{( m g / g )}$ & Reference \\
\hline PSF/HFO NPs MMMs & $6.5-7$ & 13.2 & {$[27]$} \\
PES/PDA-R UFAMs & 5.4 & 20.23 & {$[28]$} \\
$\mathrm{PES/chitosan/PVA/A-Fe} \mathrm{O}_{4} \mathrm{MMMs}$ & 6 & 40 & {$[29]$} \\
PES/HHZO nanoparticles & 5 & 104 & {$[30]$} \\
PAN/chitosan/UiO-66-NH ${ }_{2} \mathrm{MOF}$ & 6 & 115 & {$[31]$} \\
nanofibers & 6 & 145 & {$[32]$} \\
PES/PANI@GO MMMs & $7-8$ & 204.1 & {$[33]$} \\
PES/HMO MMMs & 5 & 246.96 & This study \\
SPEN porous membranes & & &
\end{tabular}

Table 4. The kinetic parameters for the adsorption of $\mathrm{Pb}(\mathrm{II})$ onto SPEN-CTAB- $0 \%$.

\begin{tabular}{ccccccc}
\hline$C_{\mathbf{0}}(\mathbf{m g} / \mathrm{L})$ & Parameters & $\mathbf{5 0}$ & $\mathbf{7 0}$ & $\mathbf{1 0 0}$ & $\mathbf{1 5 0}$ & $\mathbf{2 0 0}$ \\
\hline Pseudo-first-order & $k_{1}\left(\mathrm{~min}^{-1}\right)$ & 0.0284 & 0.0387 & 0.0450 & 0.0490 & 0.0201 \\
& $q_{\mathrm{e}}(\mathrm{cal}).(\mathrm{mg} / \mathrm{g})$ & 13.861 & 13.730 & 13.821 & 13.052 & 12.174 \\
& $q_{\mathrm{e}}(\mathrm{exp})(\mathrm{mg} / \mathrm{g})$ & 195.82 & 196.09 & 202.99 & 217.92 & 246.96 \\
& $R^{2}$ & 0.9370 & 0.9588 & 0.9712 & 0.8994 & 0.4650 \\
Pseudo-second-order & $k_{2}(\mathrm{~g} / \mathrm{mg} \cdot \mathrm{min})$ & $1.8 \times 10^{-4}$ & $3.4 \times 10^{-4}$ & $3.8 \times 10^{-4}$ & $8.1 \times 10^{-4}$ & $1.1 \times 10^{-3}$ \\
& $q_{\mathrm{e}}(\mathrm{cal}).(\mathrm{mg} / \mathrm{g})$ & 234.74 & 219.30 & 225.22 & 228.83 & 245.70 \\
& $q_{\mathrm{e}}(\mathrm{exp})(\mathrm{mg} / \mathrm{g})$ & 195.82 & 196.09 & 202.99 & 217.92 & 246.96 \\
& $R^{2}$ & 0.9896 & 0.9975 & 0.9978 & 0.9990 & 0.9951 \\
\hline
\end{tabular}


Table 4. Cont.

\begin{tabular}{ccccccc}
\hline$C_{\mathbf{0}}(\mathbf{m g} / \mathrm{L})$ & Parameters & $\mathbf{5 0}$ & $\mathbf{7 0}$ & $\mathbf{1 0 0}$ & $\mathbf{1 5 0}$ & $\mathbf{2 0 0}$ \\
\hline Intraparticle diffusion & $k_{i 1}$ & 23.188 & 28.463 & 31.556 & 44.485 & 55.225 \\
& $C$ & -5.5100 & -1.8826 & -2.4937 & -0.9429 & 10.448 \\
& $R_{1}{ }^{2}$ & 0.8930 & 0.9875 & 0.9877 & 0.9967 & 0.9446 \\
& $k_{i 2}$ & 8.5084 & 5.5405 & 4.7350 & 2.1192 & 2.2246 \\
& $C$ & 101.91 & 136.41 & 153.10 & 195.22 & 197.36 \\
& $R_{2}{ }^{2}$ & 0.9668 & 0.9819 & 0.9545 & 0.9806 & 0.3939 \\
\hline
\end{tabular}

\subsection{Adsorption Isotherm}

On the basis of equilibrium adsorption capacities $(298.15 \mathrm{~K}, \mathrm{pH}=5)$ of SPEN-CTAB-0\% to $\mathrm{Pb}$ (II) in different concentrations, Langmuir (Equation (8)) and Freundlich (Equation (9)) models were used to analyze the adsorption isotherm [1]:

$$
\begin{gathered}
\frac{C_{\mathrm{e}}}{q_{\mathrm{t}}}=\frac{1}{K_{\mathrm{L}} q_{\mathrm{m}}}+\frac{C_{\mathrm{e}}}{q_{\mathrm{m}}} \\
\ln q_{\mathrm{e}}=\ln K_{\mathrm{F}}+\frac{1}{n} \ln C_{\mathrm{e}}
\end{gathered}
$$

where $K_{\mathrm{L}}(\mathrm{L} / \mathrm{mg})$ is the Langmuir adsorption equilibrium constant and $q_{\mathrm{m}}(\mathrm{mg} / \mathrm{g})$ is the maximum adsorption capacity. $K_{\mathrm{F}}\left((\mathrm{mg} / \mathrm{g})(\mathrm{L} / \mathrm{mg})^{1 / n}\right)$ and $1 / n$ are Freundlich constants. The Langmuir model assumes that the adsorbent surface is uniform and there is no interaction among adsorbents. The adsorption process is a single layer adsorption, that is, adsorption only occurred on the surface of the adsorbent. The Freundlich model can be applied to both single-layer adsorption and non-uniform surface adsorption, which can describe the mechanism of uneven surface adsorption well $[23,26]$. According to Figure 7 and Table 5, the obtained $R^{2}$ of the Langmuir model (0.9807) was larger than that of the Freundlich model (0.8046), which indicated that the Langmuir model was more applicable to analyze the adsorption isotherm. Moreover, the maximum adsorption capacity $(281.69 \mathrm{mg} / \mathrm{g}) \mathrm{simulated}$ by the Langmuir model approached the $q_{\mathrm{m}}(246.96 \mathrm{mg} / \mathrm{g})$ obtained in the experiment. Therefore, the adsorption process of porous membranes to $\mathrm{Pb}$ (II) was monolayer adsorption. The adsorption occurred when the adsorbate collided with the empty adsorption sites, and one adsorbent occupied one adsorption site. In addition, the separation factor $R_{L}$ calculated by the Langmuir model can be used to evaluate the feasibility of the adsorption process, as in Equation (10):

$$
R_{\mathrm{L}}=\frac{1}{1+K_{\mathrm{L}} C_{0}}
$$
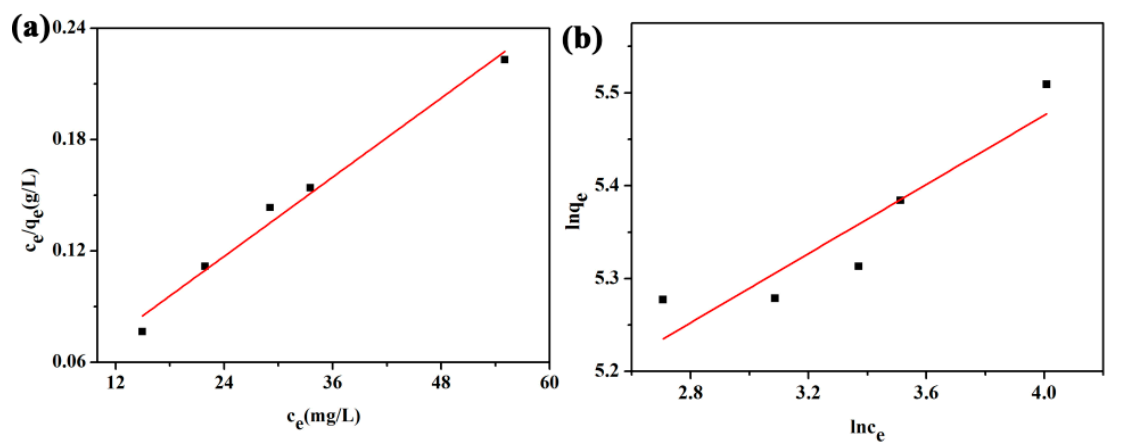

Figure 7. (a) Langmuir isotherm and (b) and Freundlich isotherm for adsorption of $\mathrm{Pb}(\mathrm{II})$ onto SPEN-CTAB- $0 \%$. 
Table 5. Langmuir and Freundlich isotherm constants for adsorption of $\mathrm{Pb}(\mathrm{II})$ onto SPEN-CTAB- $0 \%$.

\begin{tabular}{ccc}
\hline Isotherms & \multicolumn{2}{c}{ Parameters $($ Temperature $=\mathbf{2 9 8 . 1 5} \mathbf{K})$} \\
\hline Langmuir & $q_{\mathrm{m}}(\mathrm{mg} / \mathrm{g})$ & 281.69 \\
& $K_{\mathrm{L}}(\mathrm{L} / \mathrm{mg})$ & 0.1117 \\
& $R_{\mathrm{L}}$ & 0.08998 \\
$R^{2}$ & 0.9807 \\
\hline Freundlich & $K_{\mathrm{F}}\left((\mathrm{mg} / \mathrm{g})(\mathrm{L} / \mathrm{mg})^{1 / n}\right)$ & 12.861 \\
& $n^{-1}$ & 0.1861 \\
& $R^{2}$ & 0.8046 \\
\hline
\end{tabular}

When $R_{\mathrm{L}}=0$, the isotherm is irreversible, $R_{\mathrm{L}}=0 \sim 1$ is favorable, the isotherm is linear when $R_{\mathrm{L}}=1$, and $R_{\mathrm{L}}>1$ is unfavorable [26]. The $R_{\mathrm{L}}$ calculated from five different initial concentrations of $\mathrm{Pb}(\mathrm{II})$ were $0.1443,0.1210,0.08426,0.05783$ and 0.04250 , respectively. $R_{\mathrm{L}}$ was less than 1 , which demonstrated that SPEN-CTAB-0\% was favorable for the adsorption of $\mathrm{Pb}(\mathrm{II})$.

\subsection{Thermal Stability Changes before and after Adsorption}

As can be seen from Figure 8, the TGA curves of membranes changed after adsorption compared to the membranes before adsorption, which may be caused by the combination of lead ions and groups in SPEN porous membranes. The 5\% thermogravimetric temperature of porous membranes before adsorption was $430^{\circ} \mathrm{C}$, and the $5 \%$ thermogravimetric temperature had little difference after adsorption in $\mathrm{Pb}$ (II) solutions of porous membranes at different concentrations, which was about $400{ }^{\circ} \mathrm{C}$. At $600{ }^{\circ} \mathrm{C}$, the mass weight loss of the membrane before adsorption was $26 \%$ and $20 \%$ after adsorption. The results manifested the exceptional thermal stability of porous membranes.

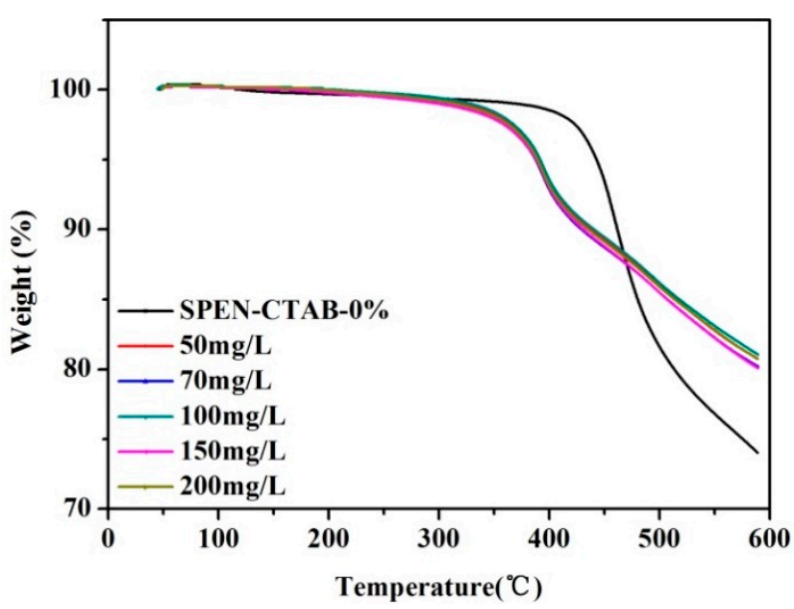

Figure 8. TGA curves of the SPEN-CTAB- $0 \%$ before and after adsorption.

\subsection{Adsorption Mechanism}

The SPEN-CTAB-0\% membrane was subjected to ATR-FTIR test (298.15 K) to gain an in-depth understanding of the adsorption reaction mechanism. The ATR-FTIR spectra of SPEN-CTAB-0\% membrane before and after adsorption of $\mathrm{Pb}(\mathrm{II})$ with a concentration of $200 \mathrm{mg} / \mathrm{L}$ are exhibited in Figure 9a,b. Moreover, the membrane after adsorption was treated using $0.2 \mathrm{~mol} / \mathrm{L} \mathrm{NaOH}$ solution to desorb $\mathrm{Pb}(\mathrm{II})$, as shown in Figure 9c.

It could be seen that the carboxylic acid absorption peaks at $1700-1650 \mathrm{~cm}^{-1}$ changed due to the carboxylic acid that converted into a carboxylate form after the membrane was treated with the solution of $\mathrm{NaOH}$. Meanwhile, the peaks at 1554 and $1399 \mathrm{~cm}^{-1}$ in Figure 9a can be classified as carboxylate adsorption peaks [40]. After $\mathrm{Pb}(\mathrm{II})$ adsorption experiment (Figure 9b), an absorption peak appeared at $1711 \mathrm{~cm}^{-1}$, the absorption peak at $1554 \mathrm{~cm}^{-1}$ disappeared, and the absorption peak at $1399 \mathrm{~cm}^{-1}$ 
was red-shifted (from 1399 to $1387 \mathrm{~cm}^{-1}$ ) and the intensity decreased. After desorption (Figure 9c), an absorption peak appeared at $1551 \mathrm{~cm}^{-1}$, and the absorption peak at $1387 \mathrm{~cm}^{-1}$ returned to $1400 \mathrm{~cm}^{-1}$, which was similar to the peak distribution of the membrane before adsorption. In addition, the absorption peaks at other locations did not change significantly. Therefore, the adsorption for $\mathrm{Pb}$ (II) by the SPEN porous membrane may occur through the complexation of $\mathrm{Pb}$ (II) with a carboxylic acid group.

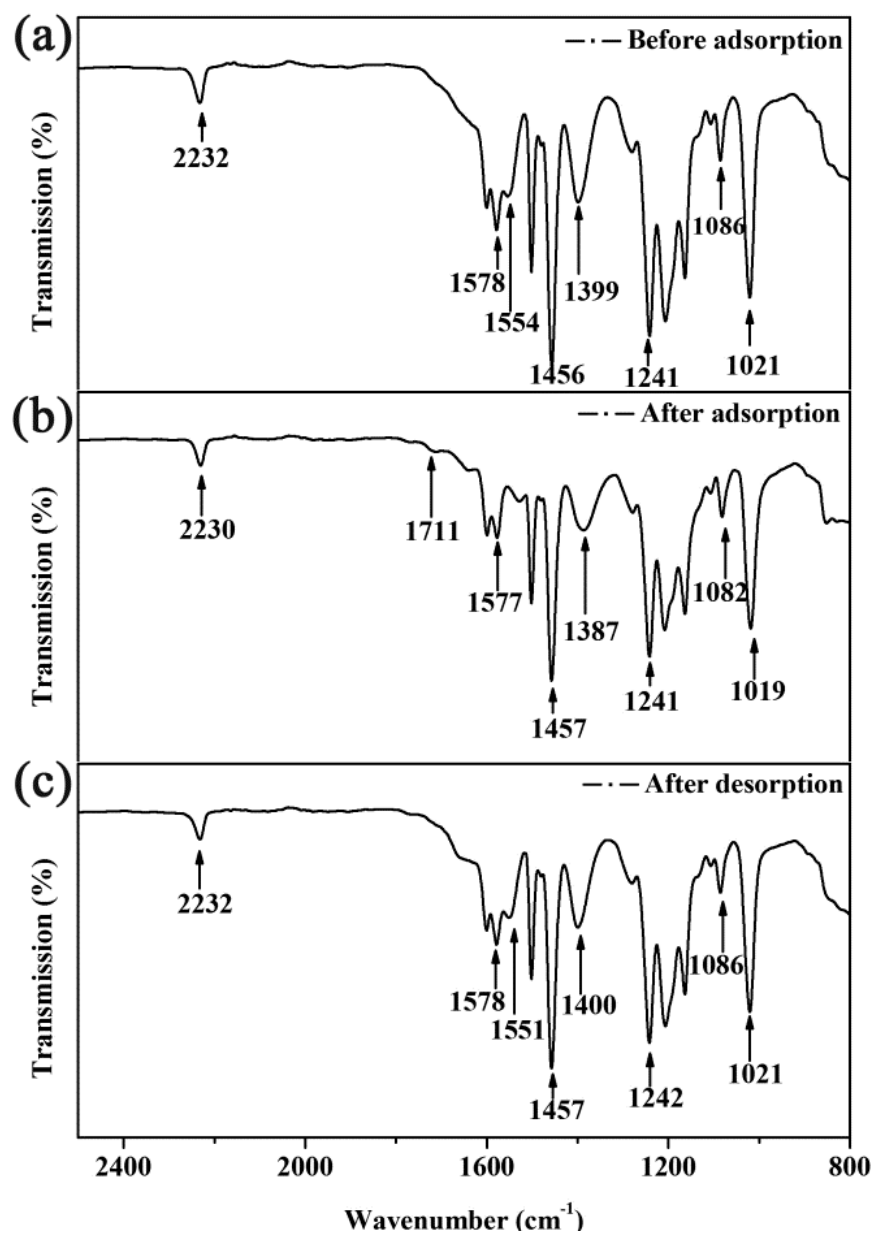

Figure 9. ATR-FTIR of SPEN-CTAB-0\% before and after adsorption and desorption.

\subsection{Recycling of SPEN Porous Membranes}

In order to ensure the objective applicability of the adsorbent, a desorption-adsorption experiment ( $298.15 \mathrm{~K}, \mathrm{pH}=5$ ) was performed on the SPEN-CTAB-0\% membrane which achieved adsorption equilibrium in $150 \mathrm{~mL}$ of $200 \mathrm{mg} / \mathrm{L} \mathrm{PbNO}_{3}$ solution. The desorption experiment was carried out using $150 \mathrm{~mL}$ of $0.1 \mathrm{~mol} / \mathrm{L} \mathrm{HCl}$ solution, $0.2 \mathrm{~mol} / \mathrm{L} \mathrm{NaOH}$ solution and deionized water as a strippant, respectively. After the membrane was desorbed, it was placed in $150 \mathrm{~mL}$ of a $200 \mathrm{mg} / \mathrm{L} \mathrm{PbNO}_{3}$ solution for re-adsorption experiments. For the purpose of obtaining a larger exchange capacity, the adsorption process was conducted by using a porous membrane soaked in $\mathrm{NaOH}$ solution. As a control experiment, the porous membrane with $\mathrm{HCl}$ as a desorption agent was also soaked in $1 \mathrm{~mol} / \mathrm{L} \mathrm{NaOH}$ solution and dried for re-adsorption. The reusability of the desorbed SPEN-CTAB- $0 \%$ membrane was examined, as shown in Figure 10. It can be seen that the adsorption capacity of SPEN-CTAB- $0 \%$ membrane with $\mathrm{HCl}$ and $\mathrm{NaOH}$ as desorption agents maintained relatively stable after five cycles. The adsorption capacity decreased from 223 to $183 \mathrm{mg} / \mathrm{g}$ after five cycles with the assistance of $\mathrm{HCl}$ as desorption agent, and the adsorption capacity decreased from 224 to $190 \mathrm{mg} / \mathrm{g}$ after five cycles 
using $\mathrm{NaOH}$ as desorption agent. However, the adsorption capacity decreased from 204 to $4 \mathrm{mg} / \mathrm{g}$ after five cycles when water acted as desorption agent. The decreased adsorption capacity probably ascribed to the covalent bond of water which was too weak and could not destroy the complexation of $-\mathrm{COO}$ and $\mathrm{Pb}(\mathrm{II})$. Therefore, the adsorption sites on the regenerated membrane were occupied by the initially adsorbed $\mathrm{Pb}$ (II), leading to poor cyclic adsorption performance. Furthermore, the desorption rate of SPEN-CTAB- $0 \%$ using water as a strippant at different time intervals is listed in Figure 11 . The desorption rate was calculated by Equation (11):

$$
\text { Desorption rate }=\frac{C_{2}}{C_{0}-C_{1}} \times 100 \%
$$

where $C_{2}$ is the concentration after desorption, $C_{0}$ is the concentration of the initial solution and $C_{1}$ is the concentration after adsorption. Figure 11 displays the $\mathrm{Pb}$ (II) desorption rate of the porous membrane with deionized water as the desorbent $(298.15 \mathrm{~K}, \mathrm{pH}=5)$ at different times. It exhibited that only $3.05 \%$ of $\mathrm{Pb}$ (II) was desorbed from the porous membrane, indicating that there were few physically adsorbed $\mathrm{Pb}(\mathrm{II})$. In other words, the chemical adsorption dominated the main place in the adsorption process of $\mathrm{Pb}$ (II) based on porous SPEN membrane, which was consistent with the results concluded from adsorption kinetics in previous work.

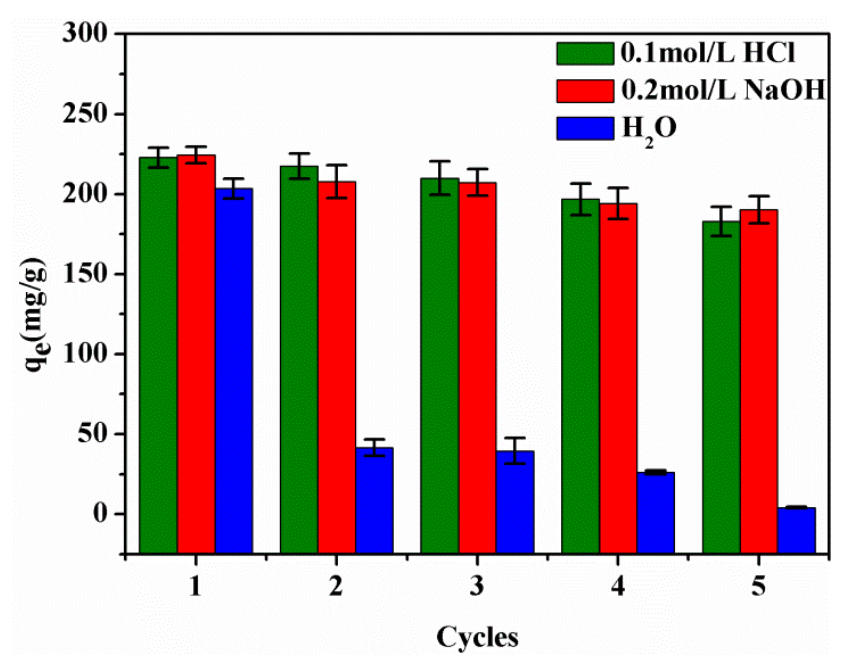

Figure 10. Regeneration of SPEN-CTAB-0\% under a different strippant.

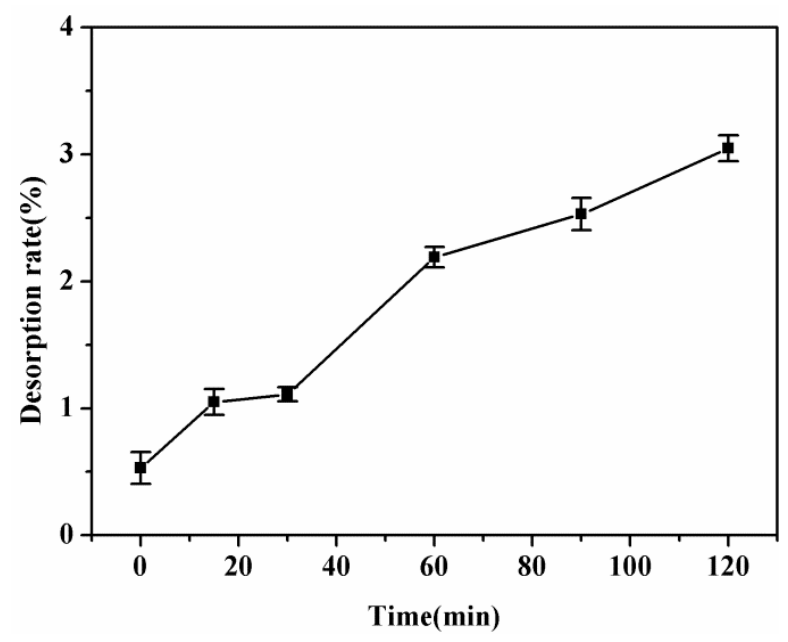

Figure 11. Desorption rate of SPEN-CTAB-0\% at different times using water as a strippant. 


\section{Conclusions}

In summary, the fabricated carboxylic acid functionalized SPEN porous membrane had a competitive adsorption capacity for $\mathrm{Pb}(\mathrm{II})$ in aqueous solution, whose adsorption capacity reached up to $246.96 \mathrm{mg} / \mathrm{g}$. We studied the effect of surfactant CTAB on the adsorption capacity. Experimental results showed that the addition of CTAB decreased the adsorption capacity of porous membranes for $\mathrm{Pb}(\mathrm{II})$. The reduced adsorption capacity was ascribed to the amount of adsorption sites on the porous membrane which were occupied by $\mathrm{CTAB}$, and the membrane may have been polluted by micelles to some extent. Furthermore, the pseudo-second-order kinetics of the adsorption of porous membranes for $\mathrm{Pb}$ (II) was obtained via kinetic simulation, which was consistent with the Langmuir single-layer adsorption model. The change of adsorption peak in ATR-FTIR spectrum indicated that the adsorption of porous membrane for $\mathrm{Pb}(\mathrm{II})$ largely profited from the carboxylic acid groups of SPEN. Moreover, the porous membranes possessed good thermal stability and high adsorption capacity after five adsorption-desorption cycles, which were up to 183 and $190 \mathrm{mg} / \mathrm{g}$ with $\mathrm{HCl}$ and $\mathrm{NaOH}$ as regeneration agents. On account of the facile preparation method, great thermal stability, high $\mathrm{Pb}(\mathrm{II})$ adsorption capacity and good cycles efficiency for adsorption, the SPEN porous membranes are expected to be applicable in the removal of $\mathrm{Pb}(\mathrm{II})$ in wastewater.

Author Contributions: Conceptualization and writing-original draft preparation, X.L. (Xiaocan Liu); methodology, X.L. (Xiaocan Liu), M.Z. and X.Z.; investigation, X.L. (Xiaocan Liu) and L.W.; resources, X.L. (Xiaobo Liu); data curation, X.L. (Xiaocan Liu), L.W. and M.Z.; writing-review and editing, L.W., X.Z. and M.Z.; validation, X.L (Xiaobo Liu).

Funding: This research was funded by Natural Science Foundation of China, grant number 51773028.

Acknowledgments: The authors wish to thank the financial support for this work provided by the Natural Science Foundation of China.

Conflicts of Interest: The authors declare no conflicts of interest.

\section{References}

1. Ji, J.; Chen, G.; Zhao, J. Preparation and characterization of amino/thiol bifunctionalized magnetic nanoadsorbent and its application in rapid removal of $\mathrm{Pb}$ (II) from aqueous system. J. Hazard. Mater. 2019, 368, 255-263. [CrossRef] [PubMed]

2. Bi, J.; Huang, X.; Wang, J.; Wang, T.; Wu, H.; Yang, J.; Lu, H.; Hao, H. Oil-phase cyclic magnetic adsorption to synthesize $\mathrm{Fe}_{3} \mathrm{O}_{4} @ \mathrm{C} @ \mathrm{TiO}_{2}$-nanotube composites for simultaneous removal of $\mathrm{Pb}(\mathrm{II})$ and Rhodamine $\mathrm{B}$. Chem. Eng. J. 2019, 366, 50-61. [CrossRef]

3. Sajjadi, S.A.; Meknati, A.; Lima, E.C.; Dotto, G.L.; Mendoza-Castillo, D.I.; Anastopoulos, I.; Alakhras, F.; Unuabonah, E.I.; Singh, P.; Hosseini-Bandegharaei, A. A novel route for preparation of chemically activated carbon from pistachio wood for highly efficient $\mathrm{Pb}$ (II) sorption. J. Environ. Manag. 2019, 236, 34-44. [CrossRef] [PubMed]

4. Feng, T.; Xu, J.; Yu, C.; Cheng, K.; Wu, Y.; Wang, Y.; Li, F. Graphene oxide wrapped melamine sponge as an efficient and recoverable adsorbent for $\mathrm{Pb}$ (II) removal from fly ash leachate. J. Hazard. Mater. 2019, 367, 26-34. [CrossRef] [PubMed]

5. Janyasuthiwong, S.; Rene, E.R.; Esposito, G.; Lens, P.N.L. Effect of $\mathrm{pH}$ on $\mathrm{Cu}, \mathrm{Ni}$ and $\mathrm{Zn}$ removal by biogenic sulfide precipitation in an inversed fluidized bed bioreactor. Hydrometallurgy 2015, 158, 94-100. [CrossRef]

6. Cronje, K.J.; Chetty, K.; Carsky, M.; Sahu, J.N.; Meikap, B.C. Optimization of chromium(VI) sorption potential using developed activated carbon from sugarcane bagasse with chemical activation by zinc chloride. Desalination 2011, 275, 276-284. [CrossRef]

7. Al-Shannag, M.; Al-Qodah, Z.; Bani-Melhem, K.; Qtaishat, M.R.; Alkasrawi, M. Heavy metal ions removal from metal plating wastewater using electrocoagulation: Kinetic study and process performance. Chem. Eng. J. 2015, 260, 749-756. [CrossRef]

8. Doggaz, A.; Attour, A.; Le Page Mostefa, M.; Tlili, M.; Lapicque, F. Iron removal from waters by electrocoagulation: Investigations of the various physicochemical phenomena involved. Sep. Purif. Technol. 2018, 203, 217-225. [CrossRef] 
9. Devlin, T.R.; Kowalski, M.S.; Pagaduan, E.; Zhang, X.; Wei, V.; Oleszkiewicz, J.A. Electrocoagulation of wastewater using aluminum, iron, and magnesium electrodes. J. Hazard. Mater. 2019, 368, 862-868. [CrossRef]

10. Wu, H.; Wu, Q.; Zhang, J.; Gu, Q.; Wei, L.; Guo, W.; He, M. Chromium ion removal from raw water by magnetic iron composites and Shewanella oneidensis MR-1. Sci. Rep. 2019, 9, 3687. [CrossRef]

11. Basu, M.; Guha, A.K.; Ray, L. Adsorption of lead on lentil husk in fixed bed column bioreactor. Bioresour. Technol. 2019, 283, 86-95. [CrossRef]

12. Dong, Q.; Guo, X.; Huang, X.; Liu, L.; Tallon, R.; Taylor, B.; Chen, J. Selective removal of lead ions through capacitive deionization: Role of ion-exchange membrane. Chem. Eng. J. 2019, 361, 1535-1542. [CrossRef]

13. Zhang, Q.; Du, Q.; Hua, M.; Jiao, T.; Gao, F.; Pan, B. Sorption enhancement of lead ions from water by surface charged polystyrene-supported nano-zirconium oxide composites. Environ. Sci. Technol. 2013, 47, 6536-6544. [CrossRef]

14. Sounthararajah, D.P.; Loganathan, P.; Kandasamy, J.; Vigneswaran, S. Adsorptive removal of heavy metals from water using sodium titanate nanofibres loaded onto GAC in fixed-bed columns. J. Hazard. Mater. 2015, 287, 306-316. [CrossRef] [PubMed]

15. Wang, X.; Zhou, K.; Ma, Z.; Lu, X.; Wang, L.; Wang, Z.; Gao, X. Preparation and characterization of novel polyvinylidene fluoride/2-aminobenzothiazole modified ultrafiltration membrane for the removal of $\mathrm{Cr}(\mathrm{VI})$ in wastewater. Polymers (Basel) 2017, 10, 19. [CrossRef] [PubMed]

16. Chen, X.; He, Y.; Fan, Y.; Zeng, G.; Zhang, L. Nature-inspired polyphenol chemistry to fabricate halloysite nanotubes decorated PVDF membrane for the removal of wastewater. Sep. Purif. Technol. 2019, 212, 326-336. [CrossRef]

17. Yu, Z.; Li, X.; Peng, Y.; Min, X.; Yin, D.; Shao, L. Mgal-layered-double-hydroxide/sepiolite composite membrane for high-performance water treatment based on layer-by-layer hierarchical architectures. Polymers (Basel) 2019, 11, 525. [CrossRef]

18. Chen, S.; Lv, C.; Hao, K.; Jin, L.; Xie, Y.; Zhao, W.; Sun, S.; Zhang, X.; Zhao, C. Multifunctional negatively-charged poly (ether sulfone) nanofibrous membrane for water remediation. J. Colloid. Interface Sci. 2019, 538, 648-659. [CrossRef]

19. Min, M.; Shen, L.; Hong, G.; Zhu, M.; Zhang, Y.; Wang, X.; Chen, Y.; Hsiao, B.S. Micro-nano structure poly(ether sulfones)/poly(ethyleneimine) nanofibrous affinity membranes for adsorption of anionic dyes and heavy metal ions in aqueous solution. Chem. Eng. J. 2012, 197, 88-100. [CrossRef]

20. Hossaini Zahed, S.S.; Khanlari, S.; Mohammadi, T. Hydrous metal oxide incorporated polyacrylonitrile-based nanocomposite membranes for $\mathrm{Cu}(\mathrm{II})$ ions removal. Sep. Purif. Technol. 2019, 213, 151-161. [CrossRef]

21. Sarker, A.K.; Cashin, P.J.; Balakrishnan, V.K.; Exall, K.; Chung, H.K.; Buncel, E.; Brown, R.S. Determining binding of sulfonamide antibiotics to CTABr micelles using semi-equilibrium dialysis. Sep. Purif. Technol. 2016, 162, 134-141. [CrossRef]

22. Daniş, Ü.; Keskinler, B. Chromate removal from wastewater using micellar enhanced crossflow filtration: Effect of transmembrane pressure and crossflow velocity. Desalination 2009, 249, 1356-1364. [CrossRef]

23. Zhan, Y.; Wan, X.; He, S.; He, Y. Sulfonated poly(arylene ether nitrile)/polypyrrole core/shell nanofibrous mat: an efficient absorbent for the removal of hexavalent chromium from aqueous solution. J. Chem. Technol. Biot. 2018, 93, 1432-1442. [CrossRef]

24. You, Y.; Liu, S.; Tu, L.; Wang, Y.; Zhan, C.; Du, X.; Wei, R.; Liu, X. Controllable fabrication of poly(arylene ether nitrile) dielectrics for thermal-resistant film capacitors. Macromolecules 2019, 52, 5850-5859. [CrossRef]

25. Wang, L.; Zheng, P.; Zhang, W.; Xu, M.; Jia, K.; Liu, X. Detection of $\mathrm{Cu}^{2+}$ metals by luminescent sensor based on sulfonated poly(arylene ether nitrile)/ metal-organic frameworks. Mater. Today Commun. 2018, 16, 258-263. [CrossRef]

26. Zhou, X.; Zheng, P.; Wang, L.; Liu, X. Preparation of sulfonated poly(arylene ether nitrile)-based adsorbent as a highly selective and efficient adsorbent for cationic dyes. Polymers (Basel) 2018, 11, 32. [CrossRef]

27. Abdullah, N.; Gohari, R.J.; Yusof, N.; Ismail, A.F.; Juhana, J.; Lau, W.J.; Matsuura, T. Polysulfone/hydrous ferric oxide ultrafiltration mixed matrix membrane: Preparation, characterization and its adsorptive removal of lead (II) from aqueous solution. Chem. Eng. J. 2016, 289, 28-37. [CrossRef]

28. Fang, X.; Li, J.; Li, X.; Pan, S.; Zhang, X.; Sun, X.; Shen, J.; Han, W.; Wang, L. Internal pore decoration with polydopamine nanoparticle on polymeric ultrafiltration membrane for enhanced heavy metal removal. Chem. Eng. J. 2017, 314, 38-49. [CrossRef] 
29. Koushkbaghi, S.; Zakialamdari, A.; Pishnamazi, M.; Ramandi, H.F.; Aliabadi, M.; Irani, M. Aminated-Fe3O4 nanoparticles filled chitosan/PVA/PES dual layers nanofibrous membrane for the removal of $\mathrm{Cr}(\mathrm{VI})$ and $\mathrm{Pb}$ (II) ions from aqueous solutions in adsorption and membrane processes. Chem. Eng. J. 2018, 337, 169-182. [CrossRef]

30. Wei, G.; Qi, J.; Lin, P.; Pan, S.; Sun, X.; Shen, J.; Han, W.; Wang, L.; Li, J. Polyethersulfone enwrapped hydrous zirconium oxide nanoparticles for efficient removal of $\mathrm{Pb}$ (II) from aqueous solution. Chem. Eng. J. 2018, 349, 500-508. [CrossRef]

31. Jamshidifard, S.; Koushkbaghi, S.; Hosseini, S.; Rezaei, S.; Karamipour, A.; Jafari Rad, A.; Irani, M. Incorporation of UiO-66- $\mathrm{NH}_{2} \mathrm{MOF}$ into the PAN/chitosan nanofibers for adsorption and membrane filtration of $\mathrm{Pb}(\mathrm{II}), \mathrm{Cd}(\mathrm{II})$ and $\mathrm{Cr}(\mathrm{VI})$ ions from aqueous solutions. J. Hazard. Mater. 2019, 368, 10-20. [CrossRef] [PubMed]

32. Ghaemi, N.; Zereshki, S.; Heidari, S. Removal of lead ions from water using PES-based nanocomposite membrane incorporated with polyaniline modified GO nanoparticles: Performance optimization by central composite design. Process. Saf. Environ. 2017, 111, 475-490. [CrossRef]

33. Jamshidi Gohari, R.; Lau, W.J.; Matsuura, T.; Halakoo, E.; Ismail, A.F. Adsorptive removal of Pb(II) from aqueous solution by novel PES/HMO ultrafiltration mixed matrix membrane. Sep. Purif. Technol. 2013, 120, 59-68. [CrossRef]

34. Zheng, P.; Xu, M.; Liu, X.; Jia, K. Sulfonated poly(arylene ether nitrile)s containing cross-linkable nitrile groups for proton exchange membranes. Solid State Ion. 2018, 316, 110-117. [CrossRef]

35. Zhou, X.; Jia, K.; He, X.; Wei, S.; Wang, P.; Liu, X. Microemulsion self-assembling of novel amphiphilic block co-polyarylene ether nitriles and photosensitizer $\mathrm{ZnPc}$ towards hybrid superparticles for photocatalytic degradation of Rhodamine B. Mater. Chem. Phys. 2018, 207, 212-220. [CrossRef]

36. Sinha, M.K.; Purkait, M.K. Enhancement of hydrophilicity of poly(vinylidene fluoride-co-hexafluoropropylene) (PVDF-HFP) membrane using various alcohols as nonsolvent additives. Desalination 2014, 338, 106-114. [CrossRef]

37. Lin, Y.F.; Chen, H.W.; Chien, P.S.; Chiou, C.S.; Liu, C.C. Application of bifunctional magnetic adsorbent to adsorb metal cations and anionic dyes in aqueous solution. J. Hazard. Mater. 2011, 185, 1124-1130. [CrossRef]

38. Sarker, A.K.; Brown, R.S. Determining binding of polycyclic aromatic hydrocarbons to CTABr micelles using semi-equilibrium dialysis techniques. Ecotoxicol. Environ. Saf. 2019, 172, 114-119. [CrossRef]

39. Acero, J.L.; Benitez, F.J.; Real, F.J.; Teva, F. Removal of emerging contaminants from secondary effluents by micellar-enhanced ultrafiltration. Sep. Purif. Technol. 2017, 181, 123-131. [CrossRef]

40. Moreira, G.F.; Peçanha, E.R.; Monte, M.B.M.; Leal Filho, L.S.; Stavale, F. XPS study on the mechanism of starch-hematite surface chemical complexation. Miner. Eng. 2017, 110, 96-103. [CrossRef] 